\title{
Parental Occupational Exposure and Risk of Acute Leukemia in Children: A Tunisian Population-Based Case-Control Study
}

\author{
H. Kalboussi ${ }^{1}$, Y. Ben Youssef ${ }^{2}$, I. Bougmiza ${ }^{3}$, F. Aloui ${ }^{2}$, A. Aloui ${ }^{1}$, W. Boughattas ${ }^{1}$, M. Maoua ${ }^{1}$,

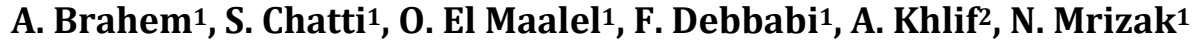 \\ ${ }^{1}$ Occupational Medicine and Occupational Pathologies Department, Farhat Hached Teaching Hospital, \\ Sousse, Tunisia \\ ${ }^{2}$ Hematology Department, Farhat Hached Teaching Hospital, Sousse, Tunisia \\ ${ }^{3}$ Community Medicine Department, Faculty of Medicine of Sousse, University of Sousse, Sousse, Tunisia \\ Email: boughattaswided@hotmail.fr
}

Received 14 December 2015; accepted 13 March 2016; published 16 March 2016

Copyright (C) 2016 by authors and Scientific Research Publishing Inc.

This work is licensed under the Creative Commons Attribution International License (CC BY).

http://creativecommons.org/licenses/by/4.0/

(c) (i) 0pen Access

\section{Abstract}

Background: In recent decades, the incidence of children's hematological malignancies has been increasing worldwide including Tunisia. Their severity is reflected in the importance of the medical, social and economic impact. This increase remains fully unexplained, and the involvement of genetic, environmental and occupational factors is strongly suspected. Materials and methods: Our study was a cross-sectional survey of the type case-control conducted in the University Hospital of Farhat Hached of Sousse during the period ranging between 1 July 2011 and 30 June 2012, and which included children with acute leukemia compared to children unharmed by neoplastic disease. Cases and controls were matched by age and gender. Our objective was to describe the socio-occupational characteristics of the parents of children with acute leukemia and to identify potential occupational factors implicated in the genesis of acute leukemia. Results: The number of acute leukemia cases in the Hematology Service and day hospital of the University Hospital of Farhat Hached during the study period was 66 cases divided into in 40 boys and 26 girls with a sex ratio of 1.53. Our cases and controls were matched by age and gender. The risk of incidence of leukemia in children from smoking fathers was higher $(p=0.02,0 \mathrm{O}=2.24, \mathrm{IC}=[1.11-4.52])$. The risk of incidence of leukemia in children from alcoholic fathers was higher with $p=0.009,0 R=3.9$; $\mathrm{CI}=[1.33$ - 11.39]. After adjusting different variables, the difference persisted significantly with pa $=0.03$ and ORa $=3.5$, ICa $=[1.09-11.6] .25 .7 \%$ of cases had a family history of blood disease and neoplasia, whereas no control presented that. The difference was statistically significant $(p=$ $0.006, \mathrm{OR}=1.46$, IC $=[1.38-1.56])$. The parental occupational exposures associated to the occurrence of acute leukemia in children were pesticides with a statistically significant difference $(p=$ $0.03, \mathrm{OR}=2.94, \mathrm{IC}=[1.06-8.13])$. This difference persisted after adjustment with different va- 
riables pa $=0.01$, ORa 3.75; ICa $=[1.27-11.03]$. This difference had become significant after adjustment with the different variables pa $=0.03,0 \mathrm{Ra}=2.67, \mathrm{ICa}=[1.06-6.7]$. Conclusion: Our results showed some support for a positive association between childhood acute leukemia risk and parental occupational exposure to pesticides and cement. Additionally, acute leukemia risk among children might be increased with parental alcohol consumption.

\section{Keywords}

\section{Occupational Medicine, Hematology, Leukemia, Children, Case Control Survey}

\section{Introduction}

The state of health of human populations is intimately linked to the integrity of the environment that surrounds them.

In the $20^{\text {th }}$ century, and with the emergence of an environmental medicine, environmental conditions constitute a fundamental explanatory factor in the field of health.

In fact, environmental medicine is a discipline that may have a prospective dimension and possibly invoke the precautionary principle and suggest optimal conditions of prevention and screening [1].

In this framework, the research is very active in an attempt to clarify the linkages that exist between the environment, especially the occupational one, and some serious diseases.

Man is currently being exposed to more than 60,000 chemical substances owing to an increasing industrial activity [2].

The majority of these substances are incriminated in the genesis of certain cancers in a significant proportion of employees and even their descendants as well [2].

Indeed, the causal link that exists between the occupational exposure of parents and the occurrence of neoplasia in children is no longer in doubt, and since infant leukemia is the most frequent malignant disease in pediatrics, and the causes of this disease are largely unknown.

Leukemia is the most commonly diagnosed cancer in children, accounting for about $30 \%$ of all cases. The incidence peaks are at age 3 years in boys and at 2 years in girls [3]. Approximately 1 in 2000 children will develop it before the age of 15 years [4].

Leukemia affects two types of white blood cells that are responsible for protecting the body from disease: lymphocytes and granulocytes. Leukemia that affect lymphocytes are known as "lymphocytic" or "lymphoblastic" and those that affect granulocytes are called "myeloid" or "myelogenous" leukemia.

Childhood leukemia is a biologically diverse disease, arrived at many different pathways. Children with leukemia (particularly ALL) have a range of different chromosomal and genetic abnormalities that define subsets of the disease with prognostic relevance [5]. Prenatal chromosomal translocations generate chimeric fusion genes (such as TEL-AML1) that are thought to be important but insufficient disease initiators since they are found in many more neonatal cord blood samples than in children who eventually develop leukemia. A "second hit" causing postnatal genetic alterations must be required to allow leukemia to develop. In the case of ALL, it is strongly suspected that this process is linked to an abnormal response to an infection [6].

The American Cancer Society estimates that 31,500 individuals in the U.S. will be diagnosed with 1 form of leukemia annually. Approximately 21,500 patients will die of their disease [7] [8]. Although the incidence of acute leukemia accounts for $<3 \%$ of all cancers, these diseases constitute the leading cause of death due to cancer in children and persons age $<39$ years [9]. The incidence varies significantly according to race and ethnic group: 14.8 cases per million blacks, 35.6 cases per million whites, and 40.9 cases per million Hispanics [10].

Acute lymphocytic leukemia (ALL) occurs approximately five times more frequently than acute myelogenous leukemia (AML) and accounts for approximately three-quarters of all childhood leukemia diagnoses [11]. Chronic myeloid leukemia makes up most of the other childhood leukemia cases.

Clinical presentation is highly variable depending on the child's age and the extent of leukemic infiltration of the bone marrow and other sites, as well as cytokine systemic effects: The classical signs of anemia, thrombo- 
cytopenia, hepatospleomegaly or lymphadenopathy are highly suspicious of leukemia but initial symptoms are often nonspecific and vague, and very similar to common, self-limiting viral illness [12]. The symptoms and signs listed below are common manifestations of the condition. There is no good evidence base to allow rational decision-making in primary care between phlebotomy and "wait-and-see" approaches when symptoms are more vague such as general malaise, fatigue and lethargy, prolonged or recurrent episodes of fever, shortness of breath and/or reduced exercise tolerance, dizziness and palpitations bleeding diathesis, particularly causing epistaxis, bleeding gums and/or easy bruising, muscular or bony pain, particularly in the legs, troublesome constipation, prolonged cough, headache Nausea and vomiting [13]. Where symptoms are prolonged, particularly troublesome, or present atypically compared with more common illnesses in children, it may be wise to conduct initial investigations. More rarely, acute leukemia can present with life-threatening complications (overwhelming sepsis (usually Gram-negative), disseminated intravascular coagulation, bleeding, pulmonary or gastrointestinal (GI) hemorrhage, acute kidney injury (secondary to hyperuricaemia), acute pulmonary oedema [13].

This pathology has been dealt with in many studies; however, no study has been conducted up to now in Tunisia to analyze the relationship between parental occupational exposure and the genesis of childhood leukemia.

In this context, we have conducted a survey whose objective has been to describe the socio-occupational characteristics of the parents of the children with acute leukemia and to determine the potential occupational factors incriminated in the genesis of such leukemia.

\section{Material and Methods}

This study has been carried out in Farhat Hached Teaching Hospital in Sousse (Tunisia) through a study of the type case-control. The cases were children with acute infant leukemia treated in the hematology ward during the period extending from July 1, 2011 until June 30, 2012. The inclusion criteria were: patients under the age of 14 years and the consent of the parents to respond to the questionnaire.

With regard to the controls, they have been recruited from among the patients admitted to the pediatric ward in the same hospital and during the same period as with the cases and who were unharmed by any neoplasia and matched to cases by age and gender.

The information has been collected through a record block, explaining:

- The socio-demographic characteristics of patients;

- Lifestyle of parents;

- Occupational history of parents: the collection of data of the occupational exposure of parents of patients has been developed by the team of occupational medicine of Farhat Hached Hospital of Sousse.

We looked for the possible occupational exposure to factors incriminated in the literature in the occurrence of acute leukemia of children namely: cutting oil/ mineral oil, plastics and resins, diesel exhaust gases, the polychlorinated biphenyls, ionizing radiation, electromagnetic waves, ethylene oxide, formaldehyde, butadiene, asbestos, crystalline silica, ceramic fibers, chrome and its derivatives, coal tar and its derivatives.

A semi-quantitative assessment of the exposure to these factors was made, taking into account: the frequency of daily exposure, the duration of exposure and the level of exposure evaluated and rated as follows:

- Normal base Level: 0;

- Light exposure: 1 ;

- Moderate exposure: 2 (direct contact with the product);

- Important exposure: 3 (very close handling).

An exposure index (I) was calculated for each substance incriminated in the literature in order to evaluate approximately the intensity of exposure for each patient to this substance. The exposure index (I) is the product of the multiplication of the number of hours of exposure per day $(\mathrm{H})$, the duration of exposure in a year $(\mathrm{D})$ and the level of exposure $(\mathrm{N})(\mathrm{I}=\mathrm{H} \times \mathrm{D} \times \mathrm{N})$.

Medical data (family and personal medico-surgical history, circumstances of the discovery of the pathology, diagnosis and histological confirmation, treatment) have been collected from the medical record of each admitted patient.

The collection of data and the interview were carried out by the same person in charge of the survey.

Data entry and analysis were carried out using the SPSS software version 17.0.

We proceeded first to the descriptive analysis of cases and controls: for this, we have represented the qualitative variables by the percentage and the quantitative variables by the average with standard deviation when the distribution was gaussian. Subsequently, we carried out a comparative study. For the univariate analysis, we 
used the Chi 2 test, Fisher's exact test, the Student's t-test. The factors considered by the univariate analysis were introduced in a multiple binary logistic regression model in order to identify the independent factors influencing the risk of development of acute childhood leukemia. The threshold of significance was set at 0.05 .

\section{Results}

The number of cases of acute leukemia colligated in the service of hematology of the Farhat Hached Teaching Hospital (Tunisia), during the period of study which is ranging between 1 July 2011 and June 30, 2012 was 66 cases divided into 40 boys and 26 girls with a sex ratio of 1.53 .

The cases and the controls are well matched according to gender, and age.

The average age of the cases was $7.83 \pm 3.48$ years versus $7.80 \pm 3.57$ years for the controls.

Half of the cases (50\%) and 56.1 per cent of the controls had a primary education level without a statistically significant difference between the two groups $(p=0.72)$.

The majority of mothers of cases and controls had a primary education level ( $48.5 \%$ and $36.4 \%$ respectively) or secondary education level $(28.8 \%$ and $50 \%$ respectively), without a statistically significant difference $(p=$ 0.06). The fathers of cases and controls had a secondary education level in $45.5 \%$ and $68.2 \%$ respectively, without a statistically significant difference $(p=0.05)$.

The cases and the controls had a socioeconomic average level in $83.3 \%$ and $97 \%$ respectively without a significant difference between the two groups.

In our study $68.2 \%$ of cases lived in the vicinity of a high voltage power line versus $71.2 \%$ of controls, with a statistically non-significant difference ( $p=0.7$, OR $=0.86$, IC $95 \%$ [0.41 - 1.82]).

No mother was alcohol and tobacco dependent in the 2 categories. The fathers of cases were smokers in $65.2 \%$ versus $45.5 \%$ of the controls with a statistically significant difference $(p=0.02)$. The risk of occurrence of leukemia among children of smoking fathers was higher with an OR $=2.24$; CI $95 \%=[1.11-4.52]$.

We have noted that $24.2 \%$ of the cases had alcoholic fathers versus $7.6 \%$ of the controls with a statistically significant difference $(p=0.009)$. The risk of occurrence of leukemia in children of alcoholic fathers was higher with an OR $=3.9$, IC $95 \%=[1.33-11.39]$.

In our study, $25.7 \%$ of the cases had a hematologic or neoplastic family history whereas no control had that. The association was statistically significant $(p=0.006)$. OR $=1.46$, IC $=[1.38-1.56]$.

The diagnosis was an acute lymphoblastic leukemia in 59 patients (89.4\%) and an acute myeloblastic leukemia in 7 patients (10.6\%).

It was noted that most of the mothers were housewives: $63.6 \%$ among the cases versus $56.1 \%$ among the controls.

For the mothers who were exercising a professional activity, they belonged mainly to the textile sector: $42.1 \%$ for cases versus $66.66 \%$ for the controls without a statistically significant difference.

The majority of mothers were exposed to incriminated toxic products before and during pregnancy: $24.2 \%$ of cases versus $27 \%$ of the controls without a statistically significant difference.

No positive association was found between the risk of occurrence of acute childhood leukemia and maternal exposure to pesticides, organic solvents, coloring agents, ionizing radiation and formaldehydes.

The exposure average index for all risk products was $119 \pm 110$ for mothers of cases versus $132 \pm 102$ for mothers of controls without a statistically significant difference $(p=0.7)$ (Figure 1 ).

Among the fathers of leukemic children, $24.2 \%$ were working in the building and public works sector versus $16.7 \%$ in the control group; and in the sector of agriculture (15.2\% versus $9.1 \%)$ without a statistically significant difference $(p=0.3)$.

More than two thirds of the fathers of children with leukemia (72.7\%) were exposed before and during their wives' pregnancies versus $48.5 \%$ among the fathers of controls with a statistically significant difference; $p=$ 0.003 .

The risk of occurrence of childhood leukemia was higher among children whose fathers were exposed to pesticides: $p=0.03, \mathrm{OR}=2.94, \mathrm{IC}=[1.06-8.13]$.

The rest of the parental exposures is detailed in Table 1.

The exposure average index for all risk products was of $191.1 \pm 113.8$ for the fathers of cases versus $110.1 \pm$ 102 for the fathers of controls with a statistically significant difference $(p=0.01)$; OR $=1.003$, IC 95\% $=[1.001$ 1.005] (Figure 2). 


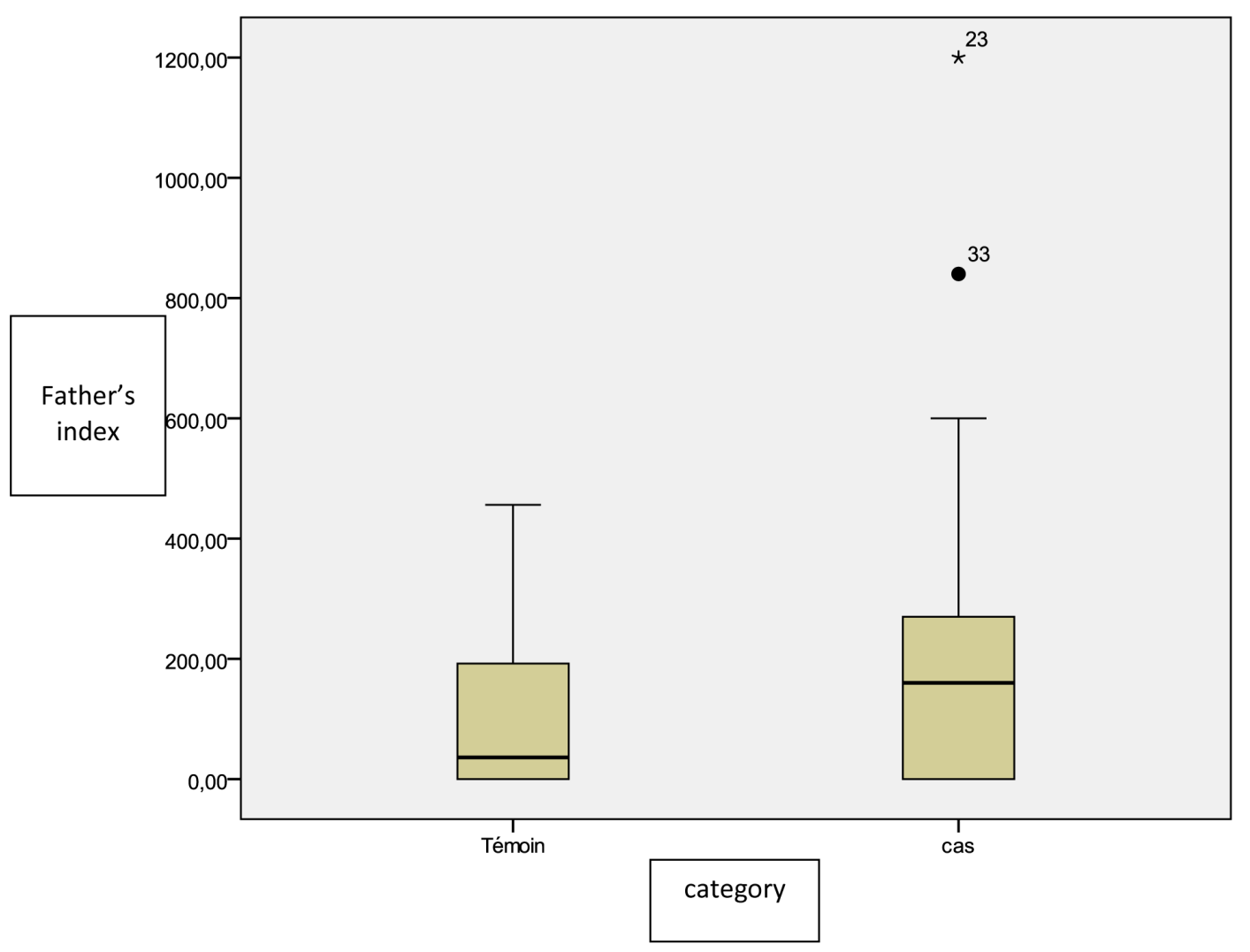

Figure 1. Distribution of the study population according to the index of exposure of fathers to all incriminated products.

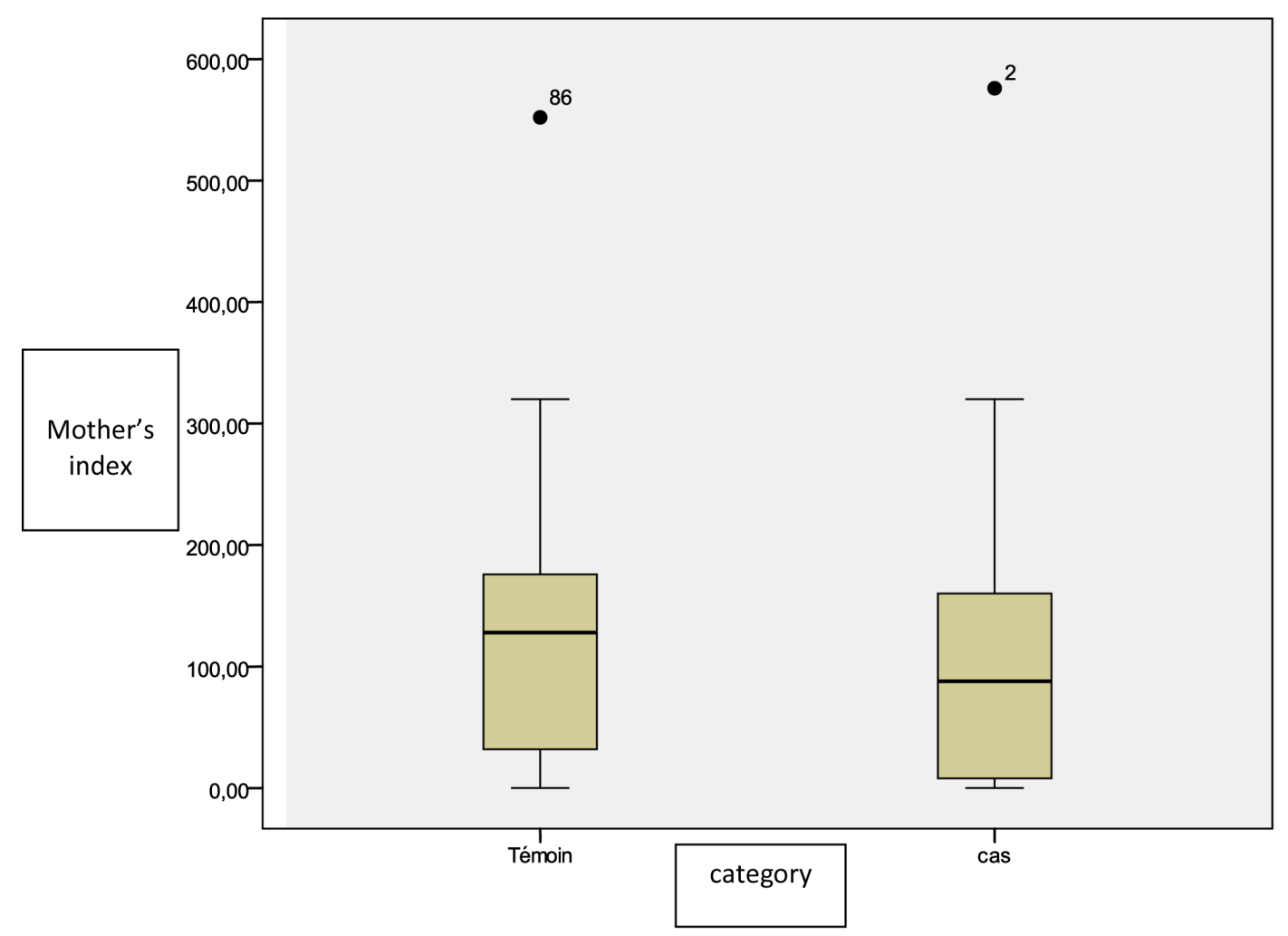

Figure 2. Distribution of cases and controls according to the index of exposure of mothers to all incriminated products. 
Table 1. Distribution of cases according to the fathers'exposure to the incriminated product.

\begin{tabular}{ccccccc}
\hline Incriminated product & \multicolumn{2}{c}{ Case } & \multicolumn{2}{c}{ Control } & & \\
& Number & Percentage & Number & Percentage & P & OR \\
\hline Solvents & 12 & 18.2 & 6 & 9.1 & 0.12 & 0.45 \\
Arsenic & 2 & 3 & 1 & 1.5 & 1 & 0.5 \\
Wood dust & 2 & 3 & 1 & 1.5 & 1 & 0.5 \\
Paints and pigments & 4 & 6.1 & 1 & 1.5 & 1 & - \\
Cutting oils/mineral oils & 3 & 4.5 & 2 & 3 & 1 & - \\
Plastics and resins & 2 & 3 & 0 & 0 & 0.5 & 1 \\
Diesel exhaust gases & 14 & 21.2 & 8 & 12.1 & 1 & 2 \\
Formaldehyde & 2 & 3 & 2 & 3 & 1 & 0.7 \\
Asbestos & 4 & 6.1 & 0 & - & - & - \\
Crystalline silica & 2 & 3 & 1 & 4.5 & 1 & 1 \\
Ceramic fibers & 2 & 3 & 1 & 1.5 & 1 & 1 \\
Chromium and its derivatives & 2 & 3 & 1 & 1.5 & 0.27 & 3.2 \\
Cement & 17 & 25.8 & 11 & 16.7 & 0.2 & 1.7 \\
\hline
\end{tabular}

In this study, we have researched the possible associations between acute childhood leukemia and the studied factors (occupational and extra-occupational).

In terms of the univariate analysis: Significant associations were found between acute childhood leukemia and the following factors:

- The paternal smoking: $p=0.02$, OR $=2.24$, IC 95\% $=[1.11-4.52]$;

- The paternal alcoholism: $p=0.009$, OR $=3.9$, IC 95\% = [1.33 - 11.39];

- Hematologic or neoplastic family history: $p=0.006$, OR = 1.46, IC = [1.38 - 1.56];

- The paternal exposure to pesticides: $p=0.03$, OR $=2.94$, IC = [1.06 - 8.13];

- The index of paternal exposure to the handled products: $p=0.01$, OR $=1.003$, IC 95\% $=[1.001-1.005]$.

After multivariate analysis (Table 2), the risk of occurrence of childhood leukemia was significantly associated with:

Paternal alcoholism: pa $=0.03$, ORa $=3.57$, IC 95\% $=[1.09$ - 11.6];

Paternal exposure to pesticides: pa $=0.01$, ORa $=3.75$, IC 95\% $=[1.27-11.03]$.

Paternal exposure to cement: pa $=0.03, \mathrm{ORa}=2.67, \mathrm{IC} 95 \%=[1.06-6.7]$.

\section{Discussion}

Our study admits certain limits:

The selection bias since only patients admitted to the service of Hematology of Farhat Hached Hospital of Sousse (Tunisia) were included in the survey where the diagnosis of leukemia was made and histologically confirmed. The leukemia patients either hospitalized or followed in other hospital services of the same hospital centers, or in other hospitals or in private clinics have not been as well included, making the extrapolation of results difficult.

The small size of our studied sample also constitutes another limit which gives an account of the difficulty of recruitment of cases and the establishment of a direct conversation with their parents.

In addition, the retrospective nature of our survey makes it difficult to establish causal links between an incriminated factor and the risk of occurrence of acute childhood leukemia; the recall bias as well as the absence of quantitative evaluation of exposures constitutes other limits in the extrapolation of our results.

However, we have included in our survey that the patients' diagnosis of acute leukemia was histologically confirmed, we have assessed the exposure in the same way among the cases and the controls and we have taken into account both the occupational and extra-occupational factors in the analysis of the risk of occurrence of acute leukemia in order to limit the effects of confounding variables. 
Table 2. Summary table of variables positively associated with the risk of occurrence of acute childhood leukemia.

\begin{tabular}{|c|c|c|c|c|c|c|}
\hline & $\begin{array}{c}\text { Case } \\
\text { Number (\%) }\end{array}$ & $\begin{array}{c}\text { Control } \\
\text { Number (\%) }\end{array}$ & $P$ & OR IC & $\mathrm{Pa}$ & ORa IC \\
\hline Smoking among fathers & $43(65.2 \%)$ & $30(45.5 \%)$ & 0.02 & $2.24(1.11-4.52)$ & - & - \\
\hline Alcoholism among fathers & $16(24.2 \%)$ & $5(7.6 \%)$ & 0.009 & $3.9(1.33$ - 11.39) & 0.03 & $3.57(1.09-11.6)$ \\
\hline $\begin{array}{l}\text { Exposure to pesticides among } \\
\text { fathers }\end{array}$ & $15(22.7 \%)$ & $6(9.1 \%)$ & 0.03 & $2.94(1.06-8.13)$ & 0.01 & $3.75(1.27-11.03)$ \\
\hline $\begin{array}{l}\text { Exposure to solvents among } \\
\text { fathers }\end{array}$ & $12(18.2 \%)$ & $6(9.1 \%)$ & 0.12 & $2.22(0.78-6.32)$ & - & - \\
\hline $\begin{array}{l}\text { Exposure to diesel exhaust gases } \\
\text { among fathers }\end{array}$ & $14(21.2 \%)$ & $8(12.1 \%)$ & 0.1 & $2.26(0.85-6.05)$ & - & - \\
\hline $\begin{array}{l}\text { Exposure to asbestos among } \\
\text { fathers }\end{array}$ & $4(6.1 \%)$ & $0(0 \%)$ & 0.11 & $\mathrm{NA}^{*}$ & - & - \\
\hline $\begin{array}{l}\text { Exposure to cement among } \\
\text { fathers }\end{array}$ & $17(25.8 \%)$ & $11(16.7 \%)$ & 0.2 & $1.7(0.7-4)$ & 0.03 & $2.67(1.06-6.7)$ \\
\hline $\begin{array}{l}\text { Index of paternal exposure to the } \\
\text { handled products }\end{array}$ & $191.1 \pm 113$ & $110.1 \pm 102$ & 0.01 & $1.003(1.001-1.005)$ & - & - \\
\hline Family history of neoplasia & $17(25.8 \%)$ & 0 & $<0.001$ & $\mathrm{NA}^{*}$ & - & - \\
\hline
\end{tabular}

*NA: not applicable.

Our study has allowed us to deduce that the children whose fathers are alcoholic and smoking, and occupationally exposed to pesticides and cement are put at the risk of occurrence of acute leukemia.

Alcoholism-smoking: The overall results of the studies converge toward the incrimination of parental smoking in the increase in the risk of occurrence of acute childhood leukemia [14]-[17]. Kyoung-Mu Lee et al. [18], in a meta- analysis of 12 epidemiological studies, have noticed an increased risk of occurrence of acute leukemia among children whose fathers are smoking $(\mathrm{OR}=1.12$, IC 95\% $=[1.04-1.21])$.

These same observations were found in a case-control study made between 1995 and 2002 in northern California by Chang JS et al. [19] (OR = 1.32, IC 95\% = [0.86 - 2.04]). Shu XO et al. [20] in their case-control study have concluded that paternal smoking one month before conception, compared to the non-smoking during the same period, has been associated with an increased risk of acute leukemia (OR $=1.56$, IC 95\% $=[1.03$ 2.36]). Similarly, the case control study done by Rudan J. et al. [21] conducted in France in 2003 has found an excess of risk with OR $=1.4$, IC $95 \%$ [1 - 1.7].

However, this bond of positive association between tobacco and childhood leukemia is still to discuss due to conflicting results found in other series. In fact, Macarthur AC et al. [22], in a case-control study made in Canada between 1990 and 1994 have not found positive association between paternal smoking and childhood leukemia. This negative association was also raised by other studies [23]-[25] which show that maternal smoking was not associated with an increased risk of occurrence of childhood leukemia.

In our study we have found a statistically significant association between paternal alcoholism and childhood leukemia $(\mathrm{OR}=3.9$, IC 95\% = [1.33 - 11.39]). Maternal alcoholism was not of excess risk.

Our results were similar to those of a case-control study conducted in Australia by Milneet E et al. [26] who found no evidence that the maternal consumption of alcohol 12 months before or during pregnancy was associated with a risk of childhood leukemia. Yet, paternal consumption of alcohol of the type beer at high levels is associated with an increased risk of leukemia.

However, our observations were not concordant with those of Shu XO et al. [20] and Macarthur AC et al. [22] who did not find a positive association with paternal alcoholism, as well as with that of Menegaux F et al. [24] which, in their case-control study made in France between 1995 and 1998, found a positive association between the maternal alcoholism and childhood leukemia.

Some studies have attempted to highlight the possible link between paternal occupational exposure to many substances and acute childhood leukemia.

Pesticides: In our series, $22.7 \%$ of the fathers of leukemic children were exposed to pesticides versus $9.1 \%$ of fathers of controls with a statistically significant difference $(p=0.03)$. 
The risk of occurrence of acute leukemia was higher among children whose fathers were exposed to pesticides (OR $=2.94$, IC 95\% = [1.06 - 8.13]) and remained high after adjustment with the different variables (ORa $=3.75$, ICa $95 \%=[1.27$ - 11.03]). However, no association was found on the part of mothers.

Our results on the link between maternal exposure to pesticides and childhood leukemia are contradictory with those found in the literature. Indeed, a meta-analysis, including 31 studies published between 1950 and 2009, made by Wigle DT et al. [27], has retained the assumption that the risk of childhood leukemia was associated with the maternal exposure to pesticides during the prenatal period with OR $=2.09$, IC 95\% $=[1.51-$ 2.88]. Monge $\mathrm{P}$ et al. [28] have also concluded that the exposure of mothers to pesticides in the year preceding conception and during the first and second trimester of pregnancy was associated with an increased risk of occurrence of acute childhood leukemia with OR = 2.4, IC 95\% = [1 - 5.9]; OR = 22, IC 95\% = [2.8 - 171.5]; OR $=4.5$, IC $95 \%=[1.4-14.7]$ respectively.

A case-control study made by Menegaux F et al. [29] in France during the period 1995-1998 about the different types of pesticides has concluded that acute leukemia observed in the 280 studied cases was significantly associated to the maternal use of insecticides in the household maintenance during pregnancy $(\mathrm{OR}=1.8$, IC 95\% [1.2 - 28]) and in gardening activities (OR = 2.4, IC 95\% [1.3 - 4.3]).

Concerning paternal exposure to pesticides and the risk of occurrence of childhood leukemia, several studies have substantiated this link such as the case control study made by Buckley J D et al. [30] including 204 cases of childhood leukemia showing that the risk of acute childhood leukemia has increased among children whose fathers were exposed more than a thousand days to pesticides with OR $=2.7$. Another case control study about 81 cases of acute childhood leukemia in Mexico, carried out by Fajardo-Gutiierrez A et al. [31] also objectified a positive association between acute childhood leukemia and paternal exposure to pesticides.

On the other hand, other studies were not concordant with our results. Indeed, in the quoted above metaanalysis by Wigle DT et al. [27], there was no overall association between childhood leukemia and none of the paternal occupational exposure to pesticides (OR $=1.09$, IC 95\% [0.88 - 1.43]). The meta-analysis of 38 case-control studies and 3 cohort studies made by Vinson F and al [32] showed no positive link between the exposure of fathers to pesticides and the incidence of leukemia among children.

A cohort study made in Sweden by Feytiching M et al. [33] found no association between the paternal exposure to pesticides and childhood leukemia.

Cement: Few studies have sought the association between parental exposure to cement and the risk of occurrence of acute childhood leukemia.

In a case-control study made in Taiwan, Reid A and al [34] noticed a positive association between the work of the fathers in the building sector and the risk of childhood leukemia; ORa = 4.08, IC 95\% = [1.12 - 14.8].

In our study, $25.8 \%$ of the fathers of leukemic children were exposed to cement versus $16.7 \%$ of control fathers with an initially non-significant difference $(p=0.2)$; OR $=1.7$, IC 95\% $=[0.7-4]$ and which became significant after adjustment with the different variables OR $=2.67$, IC 95\% $=[1.06-6.7]$.

Other substances: In the literature, several studies have been conducted with the aim to elucidate the role of several chemical substances in the occurrence of childhood leukemia. A case-control study conducted by Miligi L and al in Italy [35] has found a high risk of childhood leukemia associated with the maternal exposure to aromatic $(\mathrm{OR}=3.8)$ and aliphatic $(\mathrm{OR}=4.3)$ hydrocarbons in particular in the period of preconception. The study also showed a statistically significant risk for paternal exposure to diesel particles $(\mathrm{OR}=1.4)$, exhaust gases $(\mathrm{OR}$ $=1.4)$, and mineral oils $(\mathrm{OR}=1.7)$.

Occupational exposure of parents to the various chemicals and industrial dust has been assessed also in three German case-control studies conducted by Schuz J and al [36] from 1992 to 1997. These three studies have focused on 1138 cases of acute lymphoblastic leukemia (ALL) and 2962 controls, and they have found that maternal exposure to paints or lacquers during the period of preconception (OR = 1.6, IC 95\%, [1.1 - 2.4]) and during pregnancy (OR = 2, IC of 95\%, [1.2 - 3.3]) was linked to an increased risk of childhood leukemia.

Scientific researches continue to sort out the various factors contributing to the genesis of this childhood pathology. Among the physical causes, the ionizing radiations constitute anoncological factor of many cancers, and for childhood leukemia the findings are contradictory. Gardner MJ and al [37] have concluded that there is a risk of childhood leukemia 6 to 8 times higherreported among children whose fathers received a recorded total external dose $>100 \mathrm{mSv}$ in the six months preceding conception. The assumption of Gardner asserts that parents occupationally exposed to ionizing radiation before conception can lead to mutations in their sperm which significantly increases the risk of developing childhood leukemia. 
For maternal occupational exposure, McLaughlin JR and al [38] conducted a survey in Ontario among leukemic children (aged less than 15 years) born of mothers living in the vicinity of nuclear power stations, and concluded that there is no excess of leukemia risk arising from exposure to ionizing radiation before conception, with an $\mathrm{OR}=0.87$.

\section{Conclusions}

In conclusion, we find no evidence of an association with parental cigarette smoking and infant leukaemia. However, in contrast to some previous reports, our study supports the hypothesis that paternal alcohol consumption is associated with the risk of childhood acute leukimia; we also find that pesticide exposure may play a role in the aetiology of childhood acute leukaemia as it is already suggested by the literature.

With the results obtained from this study, we also conclude that, among the children of fathers exposed to cement at work, there seem to be a greater risk of developing acute leukimia. However, confounding factors cannot be disregarded due to incomplete control for confounding. At this stage, the consistency of our results and the results from previous studies suggests that it may be opportune to consider preventive action.

\section{Conflict of Interest}

none.

\section{References}

[1] Chevalier, P., Cordier, S., Dab, W., Gerin, M., Gosselin, P. and Quenel, P. (2003) Santé environmentale In: Gosselin, G.M., Cordier, P., Viau, S., Quénel, C., Dewailly, P. and Rédacteurs, E., Eds., Environnement et Santé PubliqueFondations et Pratiques, Edisem/Techet Doc, Acton Vale/ Paris, 59-86.

[2] Dilhuydy, J.M., Guillemart, M.H., Dilhuydy, M.H., Dohollou, N. and Robert, J. (1991) Occupational Cancers: Identification, Prevention and Repair. Concours Medical, 38, 3419-3426.

[3] Children's Cancers Incidence Statistics. Cancer Research UK. http://www.cancerresearchuk.org/health-professional/cancer-statistics/childrens-cancers/incidence

[4] Dickinson, H.O. (2005) The Causes of Childhood Leukaemia. BMJ, 330, 1279-1278. http://dx.doi.org/10.1136/bmj.330.7503.1279

[5] Forestier, E. and Schmiegelow, K. (2006) The Incidence Peaks of the Childhood Acute Leukemia Reflect Specific Cytogenetic Aberrations. Journal of Pediatric Hematology/Oncology, 28, 486-495. http://dx.doi.org/10.1097/01.mph.0000212972.90877.28

[6] Roman, E., Simpson, J., Ansell, P., et al. (2006) Childhood Acute Lymphoblastic Leukemia and Infections in the First Year of Life: A Report from the United Kingdom Childhood Cancer Study. American Journal of Epidemiology, 165, 496-504. http://dx.doi.org/10.1093/aje/kwk039

[7] Greenlee, R.T., Hill-Harmon, M.B., Murray, T. and Thun, M. (2001) Cancer Statistics. CA: A Cancer Journal for Clinicians, 51, 15-36. http://dx.doi.org/10.3322/canjclin.51.1.15

[8] Hernandez, J.A., Land, K.J. and McKenna, R.W. (1995) Leukemia, Myeloma, and Other Lymphoreticular Neoplasms. Cancer, 75, 381-394. http://dx.doi.org/10.1002/1097-0142(19950101)75:1+<381::AID-CNCR2820751320>3.0.CO;2-B

[9] Wingo, P.A., Cardinez, C.J., Landis, S.H., et al. (2003) Long-Term Trends in Cancer Mortality in the United States, 1930-1998. Cancer, 97, 3133-3275. http://dx.doi.org/10.1002/cncr.11380

[10] Lim, J.Y., Bhatia, S., Robison, L.L. and Yang, J.J. (2014) Genomics of Racial and Ethnic Disparities in Childhood Acute Lymphoblastic Leukemia. Cancer, 120, 955-962. http://dx.doi.org/10.1002/cncr.28531

[11] Zipf, T.F., Berg, S., Roberts, W.M., Poplack, D.G., Steuber, C.P. and Bleyer, W.A. (2000) Childhood Leukemias. In: Abeloff, M.D., Armitage, J.O., Lichter, A.S. and Niederhuber, J.E., Eds., Clinical Oncology, 2nd Edition, Churchill Livingston, Philadelphia, 2402-2424.

[12] Raab, C.P. and Gartner Jr., J.C. (2009) Diagnosis of Childhood Cancer. Primary Care: Clinics in Office Practice, 36, 671-684. http://dx.doi.org/10.1016/j.pop.2009.07.002

[13] Mitchell, C., Hall, G. and Clarke, R.T. (2009) Acute Leukaemia in Children: Diagnosis and Management. BMJ, 338, b2285.

[14] Belson, M., Kingsley, B. and Holmes, A. (2007) Risk Factors for Acute Leukemia in Children: A Review. Environmental Health Perspectives, 115, 138-145. http://dx.doi.org/10.1289/ehp.9023 
[15] Raidelet, L. (2011) Epidemiology of Acute Leukaemia Patients and Little Taster Ardechois Diagnosed at the Hospital Center of Valencia from 2005 to 2010. Thesis Presented for the Obtaining of the State Diploma of Doctor in Pharmacy, Faculty of Grenoble.

[16] Gahouma, D., Pendi, F., Dufillot, D., Koko, J., Mabicka-Mabicka, B., Minko-Mi-Etoua, D. and Boguikouma, J.B. (1996) Epidemiology of Cancers of Child: Experience of a Paediatric Service of the Third World. Journal of Paediatrics and Child Care, 1, 26-28.

[17] Linabery, A.M. and Ross, J.A. (2008) Trends in Childhood Cancer Incidence in the US. (1992-2004). Cancer, 112, 416-432. http://dx.doi.org/10.1002/cncr.23169

[18] Lee, K.-M., Ward, M.H., Han, S., Ahn, H.S., Soochoi, H., Shin, H.H., et al. (2009) Paternal smoking, genetic polymorphisms in CYP1A1 and Childhood Leukemia Risk. Leukemia Research, 33, 250-258. http://dx.doi.org/10.1016/j.leukres.2008.06.031

[19] Chang, J.S., Selvin, S., Metayer, C., Crouse, V., Golembesky, A. and Buffler, P.A. (2006) Parental Smoking and the Risk of Childhood Leukemia. American Journal of Epidemiology, 163, 1091-1100. http://dx.doi.org/10.1093/aje/kwj143

[20] Shu, X.O., Ross, J.A., Pendergrass, T.W., Reaman, G.H., Lampkin, B. and Robison, L.L. (1996) Parental Alcohol Consumption, Cigarette Smoking, and Risk of Infant Leukemia: A Childrens Cancer Group Study. Journal of the National Cancer Institute, 88, 24-31. http://dx.doi.org/10.1093/jnci/88.1.24

[21] Rudant, J., Menegaux, F., Leverger, G., Baruchel, A., Lambilliotte, A., Bertrand, Y., et al. (2008) Childhood Hematopoietic Malignancies and Parental Use of Tobacco and Alcohol: The ESCALE Study (SFCE). Cancer Causes \& Control, 19, 1277-1290. http://dx.doi.org/10.1007/s10552-008-9199-5

[22] MacArthur, A.C., McBride, M.L., Spinelli, J.J., Tamaro, S., Gallagher, R.P. and Theriault, G. (2008) Risk of Childhood Leukemia Associated with Parental Smoking and Alcohol Consumption Prior to Conception and during Pregnancy: The Cross-Canada Childhood Leukemia Study. Cancer Causes \& Control, 19, 283-295. http://dx.doi.org/10.1007/s10552-007-9091-8

[23] Terracini, B. and Maule, M.M. (2007) Aetiological Clues from the Descriptive Epidemiology of Childhood Acute Lymphatic Leukemia and Other Malignancies. Journal of Epidemiology \& Community Health, 61, 180-181. http://dx.doi.org/10.1136/jech.2006.047969

[24] Menegaux, F., Ripert, M., Hémon, D. and Clavel, J. (2007) Maternal Alcohol and Coffee Drinking, Parental Smoking and Childhood Leukaemia: A French Population-Based Case-Control Study. Paediatric and Perinatal Epidemiology, 21, 293-299. http://dx.doi.org/10.1111/j.1365-3016.2007.00824.x

[25] Brondum, J., Shu, X.O., Steinbuch, M., Severson, R.K., Potter, J.D. and Robison, L.L. (1999) Parental Cigarette Smoking and the Risk of Acute Leukemia in Children. Cancer, 85, 1380-1388. http://dx.doi.org/10.1002/(SICI)1097-0142(19990315)85:6<1380::AID-CNCR23>3.0.CO;2-O

[26] Milne, E., Greenop, K.R., Scott, R.J., de Klerk, N.H., Bower, C., Ashton, L.J., Heath, J.A. and Armstrong, B.K. (2013) Parental Alcohol Consumption and Risk of Childhood Acute Lymphoblastic Leukemia and Brain Tumors. Cancer Causes \& Control, 24, 391-402. http://dx.doi.org/10.1007/s10552-012-0125-5

[27] Wigle, D.T., Turner, M.C. and Krewski, D. (2009) A Systematic Review and Meta-Analysis of Childhood Leukemia and Parental Occupational Pesticide Exposure. Environmental Health Perspectives, 117, 1505-1513. http://dx.doi.org/10.1289/ehp.0900582

[28] Monge, P., Wesseling, C., Guardado, J., Lundberg, I., Ahlbom, A., Cantor, K.P., et al. (2007) Parental Occupational Exposure to Pesticides and the Risk of Childhood Leukemia in Costa Rica. Scandinavian Journal of Work, Environment \& Health, 33, 293-303. http://dx.doi.org/10.5271/sjweh.1146

[29] Menegaux, F., Baruchel, A., Bertrand, Y., Lescoeur, B., Leverger, G., Nelken, B., et al. (2006) Household Exposure to Pesticides and Risk of Childhood Acute Leukaemia. Occupational and Environmental Medicine, 63, 131-134. http://dx.doi.org/10.1136/oem.2005.023036

[30] Buckley, J.D., Robison, L.L., Swotinsky, R., Garabrant, D.H., LeBeau, M., Manchester, P., et al. (1989) Occupational Exposures of Parents of Children with Acute Non-Lymphoblastic Leukemia: A Report from the Children's Cancer Study Group. Cancer Research, 49, 4030-4037.

[31] Fajardo-Gutierrez, A., Garduno-Espinosa, J., Yamamoto-Kimura, L., Hernandez-Hernandez, D.M., Mejia-Arangure, M., Gomez-Delgado, A., et al. (1993) Risk Factors Associated with the Development of Leukemia in Children. Boletín Médico del Hospital Infantil de México, 50, 248-257.

[32] Vinson, F., Chaouki Merhi, M., Baldi, I., Raynal, H. and Gamet-Payraster, L. (2011) Exposure to Pesticides and Risk of Childhood Cancer. HAS Meat-Analysis of Recent Epidemiological Studies-Depression. Occupational and Environmental Medicine, 68, 694-702. http://dx.doi.org/10.1136/oemed-2011-100082

[33] Feychting, M., Plato, N., Nise, G. and Ahlbom, A. (2001) Paternel Occupational Exposures and Childhood Cancer. 
Environmental Health Perspectives, 109, 193-196.

[34] Reid, A., Glass, D.C., Bailey, H.D., Milne, E., Armstrong, B.K., Alvaro, F. and Fritschi, L. (2011) Parental Occupational Exposure to Exhausts, Solvents, Glues and Paints, and Risk of Childhood Leukemia. Cancer Causes \& Control, 22, 1575-1585. http://dx.doi.org/10.1007/s10552-011-9834-4

[35] Miligi, L., Benvenuti, A., Mattioli, S., Salvan, A., Tozzi, G.A., Ranucci, A., et al. (2013) Risk of Childhood Leukaemia and Non-Hodgkin's Lymphoma after Parental Occupational Exposure to Solvents and Other Agents. Occupational and Environmental Medicine, 70, 648-655. http://dx.doi.org/10.1136/oemed-2012-100951

[36] Schüz, J., Kaletsch, U., Meinert, R., Kaatsch, P. and Michaelis, J. (2000) Risk of Childhood Leukemia and Parental Self-Reported Occupational Exposure to Chemicals, Dusts, and Smoked: Results from Pooled Analyzes of German Population-Based Case-Control Studies. Cancer Epidemiology, Biomarkers and Prevention, 9, 835-838.

[37] Gardner, M.J. (1991) Father’s Occupational Exposure to Radiation and the Raised Level of Childhood Leukaemia near the Sellafield Nuclear Plant. Environmental Health Perspectives, 94, 5-7. http://dx.doi.org/10.2307/3431285

[38] McLaughlin, J.R., King, W.D., Anderson, T.W., Clarke, E.A. and Ashmore, J.P. (1993) Paternal Radiation Exposure and Leukaemia in Offspring: The Ontario Case-Control Study. BMJ, 307, 959-966. http://dx.doi.org/10.1136/bmj.307.6910.959 